\title{
Fabrikasi Directional Coupler Serat Optik Multimode
}

\author{
Samian* \\ Departemen Fisika-FMIPA, Universitas Airlangga \\ Kampus C Unair Jl. Mulyorejo Surabaya
}

Yono Hadi Pramono, Ali Yunus Rohedi, dan Gatut Yudoyono

Jurusan Fisika-FMIPA, Institut Teknologi Sepuluh Nopember

Kampus ITS Sukolilo, Surabaya 61111

\begin{abstract}
Intisari
Telah dilakukan fabrikasi directional coupler simetri 2x2 dari bahan serat optik plastik (POF) step-index multimode dengan metode fused. Bahan untuk fabrikasi directional coupler adalah serat optik plastik multimode tipe FD-620-10 dengan diameter serat $1 \mathrm{~mm}$. Fabrikasi dilakukan dengan cara memoles sepasang serat optik dengan panjang daerah interaksi kopling bervariasi dan lebar gap konstan, pasangan serat optik yang telah dipoles kemudian digabungkan. Fabrikasi menghasilkan empat buah directional coupler, salah satu directional coupler hasil fabrikasi parameternya memenuhi standar fabrikasi yaitu nilai ratio coupling 0,245 dengan toleransi dibawah $10 \%$ serta nilai excess loss lebih kecil dari $2 \mathrm{~dB}$.
\end{abstract}

KATA KUNCI: directional coupler, serat optik (POF) multimode

\section{PENDAHULUAN}

Serat optik merupakan media transmisi atau pandu gelombang cahaya berbentuk silinder yang dikembangkan diakhir tahun 1960-an sebagai jawaban atas perkembangan sistem komunikasi yang semakin lama membutuhkan bandwidh yang besar dengan laju transmisi yang tinggi [1].

Dalam perkembangannya, serat optik tidak hanya berfungsi mentransmisikan informasi saja, tetapi berkembang menjadi divais optik dengan fungsi yang lebih luas. Divais optik tersebut dapat berbentuk coupler dengan berbagai macam variannya seperti directional coupler, Y coupler dan star coupler yang berfungsi sebagai optical switching, multiplexing, demultiplexing pada perangkat WDM (Wavelength Divisiom Multiplexing) maupun beam splitter atau power divider untuk perangkat interferometer serat optik [2]. Disamping sebagai divais optik, coupler khususnya directional coupler dari bahan serat optik singlemode [3] maupun multimode [4, 5] juga dapat dimanfaatkan sebagai sensor pergeseran yang berbasis modulasi intensitas.

Perancangan directional coupler sebagai divais multiplexing pada perangkat WDM dari bahan substrat $\mathrm{LiNbO}_{3}$, gelas dan semikonduktor yang berbentuk pandu gelombang slab telah berhasil dilakukan [6] , sedangkan metode karakterisasi khususnya pengukuran rasio daya dilakukan melalui pengolahan citra medan dekat [7].

Fabrikasi directional coupler singlemode maupun multimode berbentuk pandu gelombang slab masih sangat sulit dilakukan dan membutuhkan peralatan dengan biaya yang mahal. Sementara itu directional coupler serat optik yang banyak diperlukan untuk sensor dan perangkat interferometri serat optik sangat sulit diperoleh dipasaran. Untuk men-

\footnotetext{
*E-MAIL: Mr_samian67@yahoo.com
}

gatasi kendala tersebut telah dilakukan fabrikasi directional coupler dari bahan serat optik multimode dengan diameter serat 0,5 mm menggunakan metode fused biconal taparred dengan metode konvensional [8]. Untuk kebutuhan sensor diperlukan serat optik dengan diameter serat optik yang besar agar daya optik cahaya yang terpandu juga besar [9], dalam penelitian ini dilakukan fabrikasi directional coupler serat optik step index multimode yang tergolong dalam serat optik diameter core besar (Large core optical fiber) menggunakan metode fused dengan cara memoles dua buah serat optik dengan panjang daerah polesan (daerah interaksi kopling) bervariasi dan lebar gap konstan, kemudian pasangan optik yang telah dipoles digabungkan. Penggabungan kedua serat optik dilakukan pada daerah yang telah dipoles.

\section{METODOLOGI PENELITIAN}

\section{A. Perancangan directional coupler simetri $2 \times 2$ dengan metode fused}

Desain directional coupler serat optik simetri 2 × 2 yang difabrikasi diperlihatkan pada Gambar 1. Jika port A1 pada Gambar 1 bertindak sebagai port masukan, dengan mengambil analogi teori moda terkopel untuk pandu gelombang planar singlemode [10], maka sebagian berkas cahaya (amplitudo medan) akan terkopel menuju port keluaran B2 dengan rasio kopling (ratio coupling) tertentu saat melewati daerah interaksi kopling sepanjang Lc. Berkas cahaya yang tidak terkopel akan keluar menuju port A2. Rasio kopling ditentukan oleh panjang daerah interaksi kopling (Lc) dan lebar gap antar core serat optik (g) yang digabungkan. Akibat struktur penggabungan serat optik, sebagian kecil berkas cahaya dipantulkan menuju port A1 dan B1. Rasio daya optik berkas cahaya pantulan yang menuju port B1 terhadap daya optik masukan disebut Crosstalk. Proses kopling berkas cahaya 


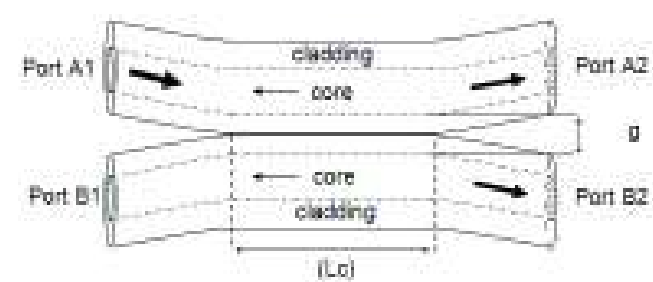

Gambar 1: Desain directional coupler simetri 2 × 2

diantara kedua serat optik menyebabkan rugi (losses) akibat struktur directional coupler. Rugi tersebut adalah rugi keluaran atau excess loss yaitu fraksi daya optik keluaran terhadap daya optik masukan dan rugi sisipan atau insertion loss yaitu fraksi daya optik pada port keluaran B2 terhadap daya optik masukan.

Mengacu pada Gambar 1, jika port A1 berfungsi sebagai port masukan berkas cahaya, maka parameter-parameter coupling ratio (CR), insertion loss (Lins), excess loss (Le) dan Crosstalk (Ct) directional coupler [11] dituliskan dalam bentuk persamaan berikut.

$$
\begin{array}{r}
C R=\frac{P_{B 2}}{P_{B 2}+P_{A 2}} \\
L_{\text {ins }}=10 \log \left[\frac{P_{A 1}}{P_{B 2}}\right] \\
L_{e}=10 \log \left[\frac{P_{A 1}}{P_{A 1}+P_{B 2}}\right] \\
C_{t}=10 \log \left[\frac{P_{A 1}}{P_{B 1}}\right]
\end{array}
$$

\section{B. Fabrikasi Directional Coupler Simetri 2 x 2 Dengan Metode Fused}

Untuk mewujudkan rancangan Directional Coupler seperti dijelaskan pada bagian sebelumnya, dibutuhkan bahan-bahan antara lain: serat optik step-index multimode tipe FD-62010 produksi Autonics, kertas penghalus (waterproof), kapas halus, alkohol $70 \%$ serta perekat polimer (lem epoxi). Sedangkan peralatan yang dibutuhkan antara lain: bangku pemolesan serat optik, holder penggabung serat optik, pemotong serat optik, pengupas jaket serat optik, cutter, lup, kaca pipet dan mikroskop dengan penggeser berskala (skala terkecil 5 $\mathrm{m})$. Karena nilai diameter inti dan cladding serta indeks bias inti dan cladding tidak tercantum pada data spesifikasi, maka untuk menentukan diameter inti dan tebal selubung dilakukan pengukuran menggunakan penggeser berskala pada mikroskop.

Prosedur fabrikasi directional coupler mengikuti langkahlangkah berikut:

1. Pemotongan serat optik sepanjang $50 \mathrm{~cm}$ sebanyak 8 buah untuk menghasilkan 4 buah directional coupler.

2. Pengupasan jaket serat optik dilakukan menggunakan alat pengupas dan cutter dengan panjang kupasan $8 \mathrm{~cm}$.

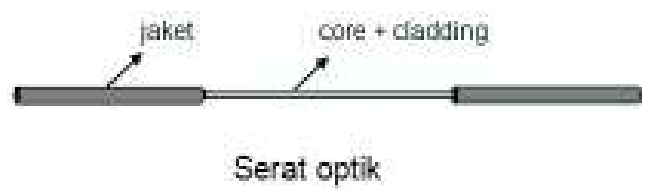

Gambar 2: Serat optik yang telah dikupas jaketnya.

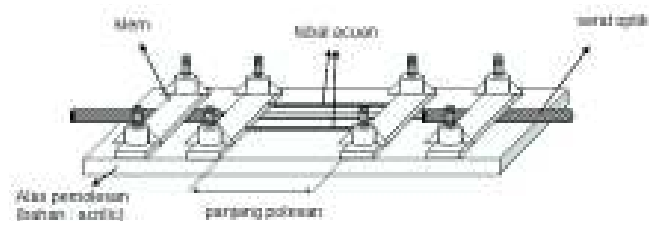

Gambar 3: Bangku pemolesan serat optik.

Serat optik yang telah dikupas jaketnya diperlihatkan pada Gambar 2.

3. Sebelum dilakukan pemolesan, serat optik yang sudah terkelupas sebagian jaketnya diletakkan pada bangku pemolesan seperti ditunjukkan pada Gambar 3. Serat optik kemudian diklem agar tidak bergeser saat dipoles. Untuk membatasi panjang polesan, pada bangku pemolesan diberi pembatas. Untuk empat buah directional coupler yang akan dibuat, panjang daerah interaksi kopling (Lc) masing-masing directional coupler yang akan difabrikasi, dalam hal ini panjang polesan, ditentukan sebesar $26 \mathrm{~mm}, 30 \mathrm{~mm}, 36 \mathrm{~mm}$ dan $40 \mathrm{~mm}$.

4. Pemolesan dilakukan menggunakan kertas penghalus sampai ketebalan serat optik mencapai tebal acuan pada bangku pemolesan seperti yang ditunjukkan pada Gambar 3. Tebal acuan terbuat dari logam keras berdiameter $0,7 \mathrm{~mm}$. Dengan demikian seluruh serat optik yang dipoles mempunyai tebal polesan sama, sehingga serat optik yang digabungkan dapat diasumsikan mempunyai lebar gap yang sama.

5. Pemolesan berikutnya dilakukan dengan menggunakan kaca pipet untuk lebih menghaluskan hasil polesan.

6. Untuk mengetahui dengan lebih teliti tebal serat op-

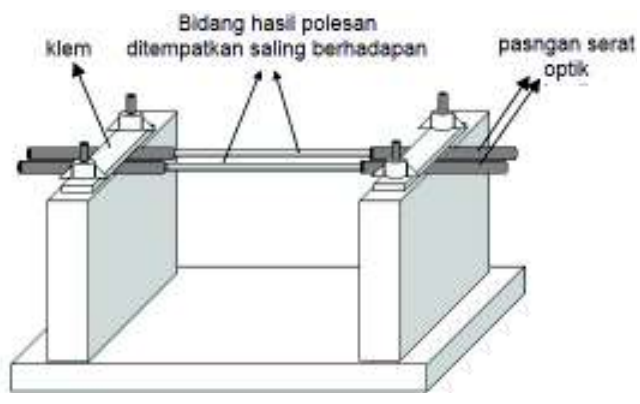

Gambar 4: Holder penggabung sepasang serat optik yang telah dipoles. 

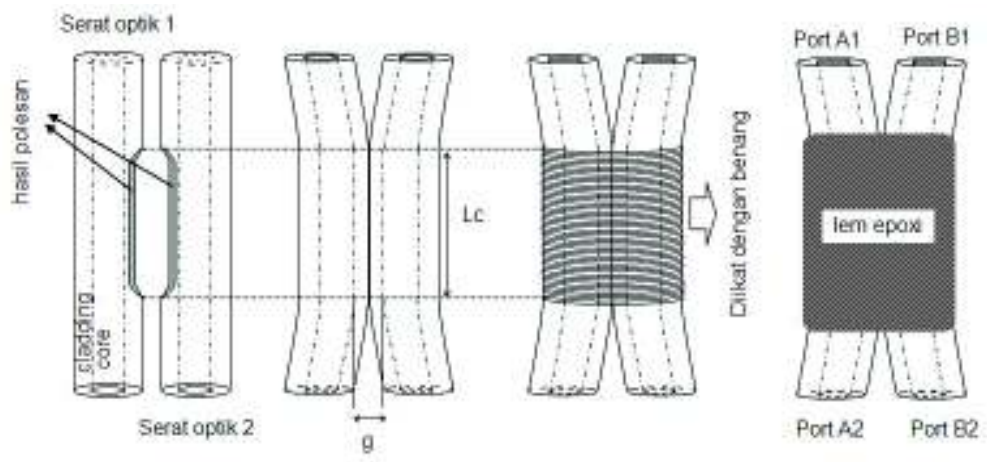

Gambar 5: Proses penggabungan sepasang serat optik yang telah dipoles.

tik yang telah dipoles, dilakukan pengukuran menggunakan mikroskop dengan penggeser berskala.

7. Penggabungan dua buah serat optik (sepasang) yang telah dipoles dengan Lc yang sama dilakukan menggunakan holder seperti ditunjukkan oleh Gambar 4.

Penggabungan dilakukan dengan meletakkan bidang polesan dua buah serat optik saling berhadapan, kemudian keduanya diikat dengan benang sepanjang Lc. Agar tidak bergeser, maka dilakukan pengeleman menggunakan lem epoxi. Proses penggabungan diperlihatkan pada Gambar 5 dengan urutan dari kiri ke kanan.

\section{Karakterisasi Directional Coupler Hasil Fabrikasi}

Directional coupler hasil fabrikasi kemudian dikarakterisasi dengan menyusun peralatan seperti ditunjukkan pada Gambar 6. Peralatan karakterisasi terdiri dari sumber laser He-Ne panjang gelombang 632,8 $\mathrm{nm}(1 \mathrm{~mW})$, detektor OPT 101 (Burr Brown), mikrovoltmeter (Leybold) untuk membaca tegangan keluaran detektor dan dua buah polarisator untuk memvariasi daya optik keluaran dari laser.

Karakterisasi dilakukan dengan cara mengumpankan cahaya keluaran laser ke port A1 (sebagai port masukan) dan mengukur daya optik keluaran dari port A2, port B1 dan port B2 secara bergantian melalui tegangan keluaran detektor yang terbaca pada mikrovoltmeter. Pencatatan dimulai dari posisi sudut polaristor $90^{\circ}$, kemudian digeser setiap $5^{\circ}$. Prosedur tersebut diulangi tetapi untuk port masukan A2, B1 dan B2 yang dilakukan secara bergantian. Data tegangan keluaran detektor kemudian dikonversi ke daya optik. Konversi dilakukan dengan cara memvariasi daya optik cahaya keluaran laser yang diumpankan ke detektor melalui sepasang polarisator dan mencatat perubahan tegangan keluaran detektor akibat variasi daya optik. Faktor konversi diperoleh dari nilai slop grafik linier daya optik terhadap tegangan keluaran detektor. Penghitungan parameter-parameter directional coupler dilakukan sesuai dengan Pers.(1) s.d Pers.(4).

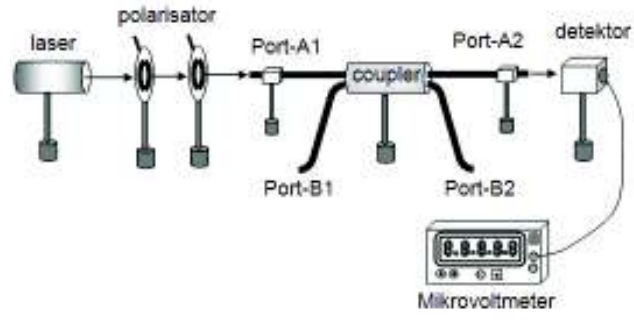

Gambar 6: Susunan alat karakterisasi directional coupler.

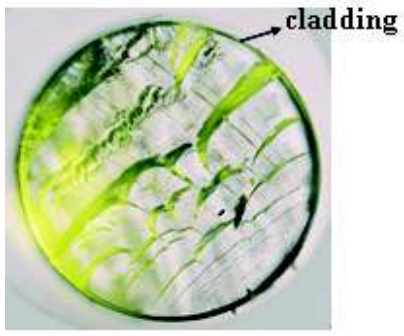

Gambar 7: Hasil rekam fotografi penampang lintang serat optik tipe FD-620-10

\section{HASIL DAN PEMBAHASAN}

Hasil perekaman fotografi penampang lintang serat optik yang digunakan diperlihatkan pada Gambar 7. Hasil pengukuran menggunakan penggeser berskala pada mikroskop menunjukkan tebal selubung serat optik sebesar $50 \mu \mathrm{m}$, sehingga diameter inti nilainya $950 \mu \mathrm{m}$. Hasil ini menunjukkan serat optik optik yang digunakan berjenis large core optical fiber. Sementara itu hasil pengukuran tebal serat optik setelah dipoles menggunakan penggeser berskala pada mikroskop menunjukkan nilai sebesar $690 \mu \mathrm{m}$. Dengan demikian lebar gap directional coupler hasil fabrikasi adalah 0. Directional coupler hasil fabrikasi diperlihatkan pada Gambar 8. Hasil konversi tegangan keluaran detektor terhadap daya optik keluaran laser diperlihatkan pada Gambar 9. 


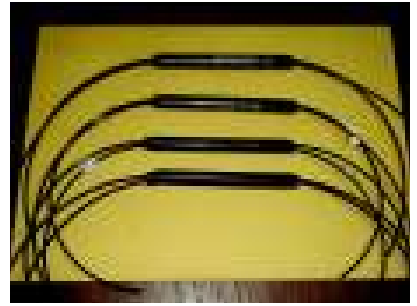

Gambar 8: directional coupler hasil fabrikasi

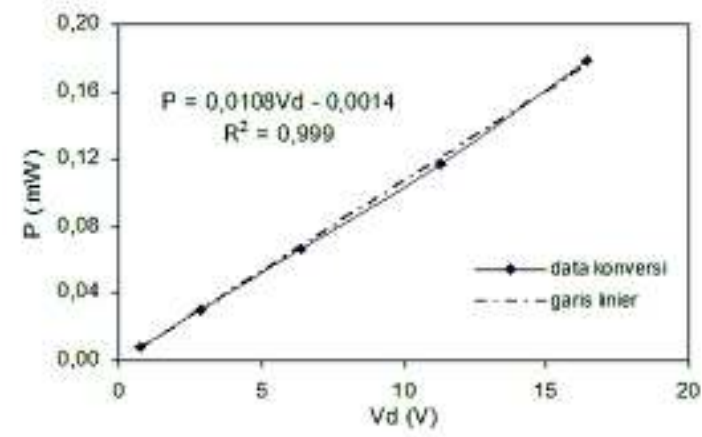

Gambar 9: Grafik konversi tegangan keluaran detektor terhadap daya optik

Hasil regresi linier menunjukkan nilai koefisien korelasi $\left(\mathrm{R}^{2}\right)$ mendekati 1 , artinya hubungan antara data daya optik terhadap tegangan keluaran detektor linier. Nilai kemiringan (slop) grafik sebesar $0,0108 \mathrm{~mW} / \mathrm{V}$ adalah faktor konversi tegangan keluaran detektor ke daya optik.

Setelah tegangan keluaran detektor hasil karakterisasi dikonversi ke daya optik, nilai parameter untuk tiap port masukan directional coupler diperlihatkan pada Tabel 1. Nilai parameter-parameter directional coupler pada Tabel 1 diperoleh menggunakan Pers.(1) s.d Pers.(4).

Pembahasan hasil fabrikasi directional coupler pada penelitian ini tidak sampai pada tinjauan teori moda terkopel, karena hal tersebut sangatlah rumit mengingat perhitungan kopling directional coupler melibatkan distribusi medan yang berbentuk fungsi Bessel dengan jumlah moda sangat besar.

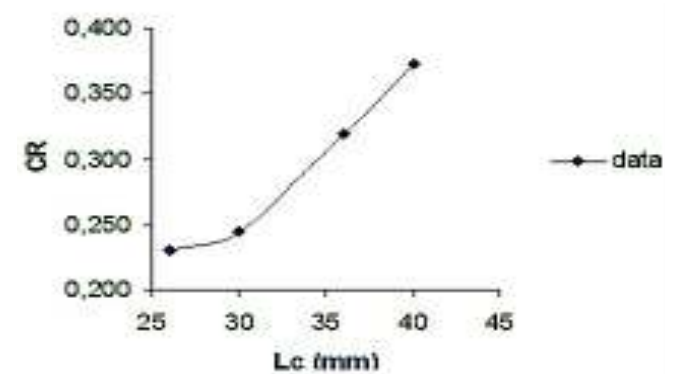

Gambar 10: Grafik hubungan panjang daerah interaksi kopling terhadap rasio kopling
TABEL I: Nilai parameter untuk tiap port masukan directional coupler (DC) hasil fabrikasi

\begin{tabular}{cccccccc}
\hline \hline DC & $\begin{array}{c}\mathrm{L}_{c} \\
(\mathrm{~mm})\end{array}$ & $\begin{array}{c}\text { Port } \\
\text { in }\end{array}$ & $\begin{array}{c}\text { Port } \\
\text { Out }\end{array}$ & CR & $\begin{array}{c}\mathrm{C}_{t} \\
(\mathrm{~dB})\end{array}$ & $\begin{array}{c}\mathrm{L}_{\text {ins }} \\
(\mathrm{dB})\end{array}$ & $\begin{array}{c}L_{e} \\
(\mathrm{~dB})\end{array}$ \\
\hline \multirow{4}{*}{1} & \multirow{2}{*}{26} & & & & & & \\
& & A1 & A2,B2 & 0,210 & 27,775 & 8,673 & 1,867 \\
& & B1 & A2,B2 & 0,241 & 27,111 & 8,553 & 2,375 \\
& & A2 & A1,B1 & 0,209 & 26,847 & 8,493 & 1,636 \\
& & B2 & A1,B1 & 0,248 & 27,949 & 9,018 & 3,094 \\
& 30 & A1 & A2,B2 & 0,251 & 26,245 & 7,509 & 1,510 \\
& & B1 & A2,B2 & 0,234 & 25,524 & 7,794 & 1,494 \\
& & A2 & A1,B1 & 0,223 & 24,956 & 7,941 & 1,419 \\
& & B2 & A1,B1 & 0,271 & 25,967 & 6,741 & 1,064 \\
& 36 & A1 & A2,B2 & 0,354 & 28,634 & 7,239 & 2,731 \\
& & B1 & A2,B2 & 0,310 & 29,246 & 7,757 & 2,670 \\
& & A2 & A1,B1 & 0,354 & 27,284 & 7,168 & 2,655 \\
& & B2 & A1,B1 & 0,258 & 28,317 & 8,068 & 2,182 \\
4 & 40 & A1 & A2,B2 & 0,375 & 28,838 & 7,421 & 3,162 \\
& & B1 & A2,B2 & 0,353 & 28,816 & 7,880 & 3,361 \\
& & A2 & A1,B1 & 0,346 & 28,235 & 7,973 & 3,360 \\
& & B2 & A1,B1 & 0,416 & 26,612 & 6,094 & 2,274 \\
\hline \hline
\end{tabular}

Sedangkan medan yang terkopel merupakan medan moda orde tinggi [12].

Hasil karakterisasi masing-masing directional coupler memperlihatkan nilai $\mathrm{CR}, \mathrm{C}_{t}, \mathrm{~L}_{i n s}$ dan $\mathrm{L}_{e}$ tidak sama untuk tiap port masukan. Perbedaan nilai-nilai tersebut terjadi karena ketaksimetrisan sepanjang Lc dan daerah ujung polesan pada saat proses penggabungan pasangan serat optik. Ketaksimetrisan terjadi akibat struktur permukaan serat optik hasil polesan yang tidak rata dan panjang Lc yang tidak sama (dalam orde kecil) untuk sepasang serat optik yang digabungkan. Hal tersebut sangat wajar karena fabrikasi dilakukan secara konvensional. Nilai rata-rata parameter tiap directional coupler hasil fabrikasi diperlihatkan pada Tabel 2.

TABEL II: Nilai rata-rata parameter directional coupler hasil fabrikasi

\begin{tabular}{ccccccc}
\hline \hline $\begin{array}{c}\text { Directional } \\
\text { coupler }\end{array}$ & $\begin{array}{c}\mathrm{Lc} \\
(\mathrm{mm})\end{array}$ & $\mathrm{CR}$ & $\begin{array}{c}\text { Toleransi } \\
(\%)\end{array}$ & $\begin{array}{c}\mathrm{C}_{t} \\
(\mathrm{~dB})\end{array}$ & $\begin{array}{c}\mathrm{L}_{\text {ins }} \\
(\mathrm{dB})\end{array}$ & $\begin{array}{c}\mathrm{L}_{e} \\
(\mathrm{~dB})\end{array}$ \\
\hline 1 & 26 & 0,230 & 8,715 & 27,421 & 8,684 & 2,243 \\
2 & 30 & 0,245 & 6,639 & 25,673 & 7,496 & 1,372 \\
3 & 36 & 0,319 & 10,972 & 28,370 & 7,558 & 2,560 \\
4 & 40 & 0,373 & 6,174 & 28,125 & 7,342 & 3,039 \\
\hline \hline
\end{tabular}

Nilai toleransi CR diperoleh dari prosentase CR tiap port masukan terhadap nilai rata-rata $\mathrm{CR}$ directional coupler. Grafik hubungan Nilai Lc terhadap nilai CR diperlihatkan pada Gambar 10. Gambar 10 memperlihatkan bahwa bertambahnya nilai Lc memperbesar nilai CR.

Tinjauan secara makro adalah dengan membandingkan nilai parameter-parameter directional coupler hasil fabrikasi pada Tabel 2 terhadap nilai standart fabrikasi directional coupler multimode. Nilai standart untuk $\mathrm{CR} \leq 0,5$, toleransi CR $\leq 10 \%, \mathrm{C}_{t}>40 \mathrm{~dB}$ dan $\mathrm{L}_{e}<2 \mathrm{~dB}$ [13] . Dari data pada Tabel 2 , nilai $\mathrm{C}_{t}$ keempat directional coupler belum memenuhi standart. Untuk nilai toleransi CR, kecuali directional coupler 3 
sudah memenuhi standart. Sedangkan untuk nilai $\mathrm{L}_{e}$, hanya directional coupler 2 yang memenuhi standart.

Nilai $\mathrm{C}_{t}$ belum memenuhi standar karena bentuk ujung polesan yang mengerucut dan terlalu curam mengakibatkan ketidaksempurnaan pada proses penggabungan dan membentuk daerah pantulan yang cukup besar. Faktor tersebut dapat diperbaiki dengan melandaikan daerah ujung polesan, sehingga terbentuknya daerah pantulan dapat diperkecil. Dengan demikian hasil fabrikasi directional coupler serat optik multimode menggunakan metode fused dengan cara memoles serat optik pada penelitian ini menghasilkan divais optik yang dapat difungsikan sebagai splitter pada sistem komunikasi optik jarak pendek yaitu directional coupler 2. Sedangkan tiga directional coupler lainnya dapat digunakan sebagai power divider maupun sensor [5].

\section{SIMPULAN}

Berdasarkan hasil penelitian dan pembahasan yang telah dijelaskan, maka dapat disimpulkan bahwa directional coupler serat optik multimode dapat difabrikasi menggunakan metode fused dengan cara memoles serat optik dengan hasil yang layak digunakan sebagai divais pada sistem komunikasi optik jarak pendek maupun sebagai sensor.
[1] Suematzu,Y., Iga, K., Introduction to Optical Fiber Communication (John Willey \& Sons, Inc., 1982).

[2] Farrel, G., Optical Communication System Optical Fibre Coupler and Switche (Dubblin Institute of Technology, 2002).

[3] Baruch, M.C., Gerdt, D.W., Adkins, C.M., Fiber Optic Couplers Displacement Sensor, Procceding SPIE 2002.

[4] Vijay K.K, Anandkumar S.L., I.I. Pattanashetti, U.S. Raikar, Journal of Optoelectronics and Advance Materials 8, 4 (2006).

[5] Samian, Yono H.P., Ali Yunus R., Directional Coupler Sebagai Sensor Pergeseran Mikro, Procceding SNAF 2008.

[6] Rohedi, A.Y., Perancangan Directional Coupler Untuk Aplikasi WDM Struktur $4 x$ 4, Thesis S-2, Universitas Indonesia 1997.

[7] Uranus, H.P., Januar, I.P., Pengukuran Power Rasio dari Devais Fotonik Berkeluaran Banyak Melalui Pengolahan Citra Medan
Dekat, Seminar Nasional Optoelektronika, Jakarta 1997.

[8] Supadi, Yono, H.D., Gatut, Y. , JFA 2, 1 (2006).

[9] Krohn, D.A, Fiber Optik Sensor, Fundamental and Aplication, 3rd (ISA, New York, 2000).

[10] Saleh, B.H.A., Teich, M.C., Fundamental of Photonics ( John Wiley \& Sons, Inc., 1991)

[11] Fernando, X., Adroit Group, Lecture handout : WDM Concept and Component, Ryerson University (2007).

[12] Tamir, T., Guide-Wave Optoelectronics, 2ed (Springer - Verlag, New York, 1990).

[13] Hoss, R.J., Fiber Optics, 2ed (Prentice - Hall, New Jersey, 1993). 